\title{
Antidepressant use and the components of the frailty syndrome
}

Vanessa Adelina Casali Bandeiral

Evelise Moraes Berlezi ${ }^{2}$

Carolina Baldissera Gross'

Christiane de Fátima Colet ${ }^{2}$

\section{Abstract}

Objective: to evaluate the effects of antidepressant use on components of frailty. Methods: a cross-sectional and analytical study comparing groups of users and non-users of antidepressants was carried out in a municipal region in the south of Brazil. The research was linked to the matrix study "Health of Elderly Persons in Primary Care". The sample was selected through access to the database of the matrix study from which two groups were extracted: users $(\mathrm{n}=87)$ and non-users $(\mathrm{n}=114)$ of antidepressants. After selection of the groups, data collection was carried out between June and September 2016 in the homes of the elderly, and included information on sociodemographic characteristics, use of medications and the evaluation of frailty. Pearson's Chi-square hypothesis test was used to verify the association between the groups and the Odds Ratio (OR) was used to calculate risk. Results: The prevalence of frailty was $62.7 \%$ and was associated with the group that used antidepressants. Among the components of frailty an association between the user group and fatigue, low gait speed and unintentional weight loss was found. A greater risk of frailty among elderly persons using tricyclic antidepressants and antidepressants potentially inappropriate for the elderly was identified. Conclusions: an association between frailty and antidepressant use was found. These results indicate the need for the clinical evaluation of the risks and benefits of prescribing antidepressants for the elderly; and reveal that when treatment begins, the monitoring and assessment of geriatric characteristics are required to ensure the safety and quality of life of the elderly.

\footnotetext{
Universidade Regional do Noroeste do Estado do Rio Grande do Sul, Programa de Pós-graduação stricto sensu em Atenção Integral à Saúde. Ijuí, RS, Brasil.

2 Universidade Regional do Noroeste do Estado do Rio Grande do Sul, Departamento de Ciências da Vida. Ijuí, RS, Brasil.

Keywords: Antidepressive Agents. Primary Health Care. Frail Elderly. 


\section{INTRODUCTION}

Frailty is a multidimensional syndrome that involves the interaction of biological and psychosocial factors ${ }^{1,2}$. This syndrome, proposed by Fried et al. ${ }^{3}$, is characterized by a decline in energy and is related to changes in the musculoskeletal, neuroendocrine and immunological systems, which especially affect muscle loss, appetite changes and chronic inflammatory conditions. According to these authors, the frailty phenotype involves five components: unintentional weight loss, fatigue, a decrease in grip strength, slow gait speed and a low level of physical activity $^{3}$.

In general, frailty is a high vulnerability factor for adverse health events such as disability, dependence, falls, hospitalization, long-term care and death ${ }^{4}$. Although frailty is related to physiological changes characteristic of senescence, it is also determined by the presence of chronic diseases and psychosocial determinants. It is worth mentioning that there is an increased risk of frailty in elderly women of an advanced age, low-income elderly persons, those who use three or more drugs, those suffering cognitive and functional decline and when symptoms indicative of depression are present ${ }^{1,2,5}$.

Specifically, the presence of depressive symptoms and major depression are the most common psychiatric disorders among the elderly. The metaanalysis of Barcelos-Ferreira et al. ${ }^{6}$ identified a prevalence of the diagnosis of major depression and symptoms suggestive of depression in $7.0 \%$ and $26.0 \%$ of Brazilian elderly persons, respectively. Consequently, antidepressants are often employed in the treatment of this disorder. The Longitudinal Study of Adult Health (ELSA) identified the use of antidepressants in $6.87 \%$ of the Brazilian adult population? ${ }^{7}$. This percentage increases in the elderly population, with frequencies of use between $7.2 \%$ and $23.6 \%{ }^{8,9}$.

Although the consumption of antidepressants in the elderly is high, important systematic reviews by Briana et al. ${ }^{10}$ and Benraad et al. ${ }^{11}$ found that there is a lack of studies that relate the use of antidepressants and frailty. Briana et al. ${ }^{10}$ concluded that the studies performed to date do not confirm or refute the association between antidepressant and frailty. Benraad et al. ${ }^{11}$, meanwhile, found that randomized clinical trials of the antidepressant treatment of major depression in the elderly did not consider geriatric characteristics, such as frailty, as a possible effect modifier or in the evaluation of potential adverse effects on this condition.

A follow-up study by Lakey et al. ${ }^{12}$ with women in the USA, however, identified the association between antidepressant use and the occurrence of frailty, both in the presence and absence of depressive symptoms; it was observed in this study that antidepressant users are almost twice as likely to be frail. A study by Groot et al. ${ }^{13}$, meanwhile, identified a moderate association between antidepressant use and gait impairment, one of the components of the frailty syndrome, but did not compare the risk of one group over the other. Although the scientific evidence therefore shows that there is an association between the use of antidepressants and the occurrence of frailty, the two studies found were performed with North American and European populations. In addition, they did not examine all the components of the frailty syndrome. Considering the heterogeneity of the Brazilian population and its specific characteristics of aging, epidemiological research that investigates the use of drugs and their repercussions on the senescent body are required.

From these considerations, the present study aimed to evaluate the repercussion of the use of antidepressants on the components of frailty.

\section{METHOD}

A cross-sectional and analytical study comparing groups of users and non-users of antidepressants was undertaken. The present study was carried out in a municipal region located in the south of Brazil, linked to the matrix survey The Health of the Elderly in Primary Care.

The study population of the matrix survey was made up of elderly people aged 60 and over, of both genders, registered in the twelve Family Health Strategy (FHS) units of the urban area of the municipal region. The sample of this study was probabilistic, and the elderly persons were selected through a proportional stratified sampling technique by FHS and gender. A representativeness of $12 \%$ was assured, defined by the population aging rate of 
the region. To establish the sample size, data from the Basic Care Information System ${ }^{14}$ were used. In 2014 , the number of elderly enrolled in the FHS was 5,269 , meaning that considering a sample error of $5 \%$ and a test power of $80 \%$, a sample of 636 elderly persons was required ${ }^{15}$.

In the first stage of the study, the database of the matrix survey was accessed to identify users and non-users of antidepressants to compose the analysis groups. Two paired groups were established based on the number of subjects for the selection process in the database. A total of 140 elderly persons who used antidepressant or anxiolytic agents, whether or not in combination with other drugs, were identified and allocated to the user group. For each such elderly person in the "user" group, meanwhile, a non-user elderly person was randomly selected. The two groups were chosen from the same study population.

In the second stage, data collection was carried out in the households of the elderly persons between June and September of 2016. At this stage, those who had ended treatment with these drugs more than 30 days after the interview date were excluded from the user group. In the non-user group, elderly persons who used antidepressant or anxiolytic medication at some point in their life were excluded. Also excluded were those who did not possess the physical and/ or mental capabilities to carry out the research protocol. For this study we selected only elderly users of antidepressants, with 87 elderly persons in the user group and 114 individuals in the non-user group. A total of 53 elderly persons were excluded from the user group. Of these, 21 used anxiolytic medication, while the other losses in both groups were because they did not meet the study criteria.

The variables of interest of the study were sociodemographic characteristics (age, gender, marital status, schooling and income); health conditions: presence of chronic disease (self-reported) and symptoms of depression (Geriatric Depression Scale) ${ }^{16}$; data on drug use (number of drugs used, the active principle and class of antidepressant, and the use of potentially inappropriate antidepressant); and classification of frailty and its components (unintentional weight loss in the previous year, grip strength, gait velocity, physical activity level and self-reported fatigue). The variables were obtained through a household survey.
For the identification of antidepressants, the third and fourth levels of the Anatomical Therapeutic Chemical (ATC) classification was used ${ }^{17}$. The use of potentially inappropriate antidepressants was identified according to the Beers criteria updated by the American Geriatrics Society ${ }^{18}$.

The components and frailty classification were obtained from the matrix survey database, after the construction of the user and non-user groups. It should be noted that five months elapsed between the physical evaluation of frailty and the obtaining of the variables of the present study. To evaluate frailty, the criteria established by Fried et al. ${ }^{3}$ were used: unintentional weight loss, gait speed, grip strength; level of physical activity; and self-reported fatigue. The elderly were classified into two categories: frail elderly persons (who presented one or more of the frailty criteria); and non-frail elderly persons (did not present any of the frailty criteria).

Unintentional weight loss, obtained by selfreporting, refers to unintentional weight loss in the last 12 months, using the loss of 4.5 kilograms or $5 \%$ of body weight as a cut-off 3 .

Grip strength was evaluated through a dynamometer. Low grip strength values were those that were $20 \%$ lower than the mean values of three measurements performed, adjusted by gender and body mass index (BMI) $\left(\mathrm{Kg} / \mathrm{m}^{2}\right)^{19}$.

Gait speed indicated the time in seconds that each elderly person took to walk 4.6 meters using their usual steps. Low gait speed was verified by a $20 \%$ greater time taken to walk such a distance, from an average of three attempts by each elderly person, adjusted by the median height for men and women ${ }^{20}$.

Fatigue was assessed through questions taken from the CES-D (Center for Epidemiological Studies - Depression), namely: (1) do you feel that you have to make an effort to carry out your usual tasks; (2) that you cannot carry out your activities ${ }^{19}$.

Level of physical activity was identified based on items from the Minnesota Leisure Time Activity Questionnaire. Active individuals were those who performed 120 minutes of physical exercises and/or sports of vigorous intensity per week, which were those equivalent to values greater than 6 Metabolic 
Equivalents (MET); which is the energy expenditure indirectly calculated by the instrument; or those who accumulated more than 150 minutes per week in moderate intensity physical exercise and sports (from $\geq 3$ MET to $\leq 6 \mathrm{MET})^{21}$.

Descriptive statistics tools were used, such as measures of central tendency (mean) and dispersion measures (standard deviation and 95\% confidence interval $(95 \% \mathrm{CI})$, and relative and absolute frequency for the qualitative variables. To verify the association between two or more qualitative variables, Pearson's Chi-square hypothesis test was used and the Odds Ratio (OR) was used to calculate the risk, with an OR equal to or greater than 1.5 considered a risk. For all tests, a significance level of 5\% was applied.

All the ethical precepts recommended for research with human beings were observed and the study was approved by the Ethics and Research Committee under Approval Number No 1.570.165/2016.

\section{RESULTS}

The study included 201 elderly persons, 43.3\% (87) in the user group and $57.7 \%$ (114) in the nonuser group. The mean age was $71.8 \pm 7.61$ years (CI $95 \%$ 70.74-72.86). The prevalent sociodemographic and health characteristics included the female gender $(66.2 \%)$, those with a partner $(69.2 \%)$, the presence of chronic disease $(79.6 \%)$ and the absence of symptoms suggestive of depression (78.1\%) (Table 1).

The prevalence of frailty was $62.7 \%$ (126) of the elderly persons and there was an association between antidepressant use and frailty ( $p=0.005)$. A total of $73.6 \%$ (64) of the user group were frail, while $54.4 \%$ (62) of the non-users suffered from the syndrome. In addition, it was found that elderly users of antidepressants were twice as likely to be frail than non-users (OR 2.33 CI 95\% 1.28-4.26). When intragroup analysis for the presence of symptoms suggestive of depression and frailty was performed, no association was identified in the user $(p=0.078)$ or non-user groups $(p=0.140)$.

Among the components of the frailty syndrome, fatigue and low gait speed occurred most frequently among the elderly in the study, with a prevalence of $35.4 \%$ and $23.4 \%$, respectively. Associations were found between the use of antidepressants and the fatigue, low gait speed and unintentional weight loss components. In terms of risk, it was found that members of the user group were three times more likely to lose weight and twice as likely to suffer frailty and slow gait speed than non-users, as shown in Table 2.

Table 1. Sociodemographic and health characteristics of elderly users and non-users of antidepressives $(\mathrm{N}=201)$ from a municipal region in the south of Brazil, 2016.

\begin{tabular}{llll}
\hline Variables & $\begin{array}{l}\text { Total } \\
\%(\mathrm{n})\end{array}$ & $\begin{array}{l}\text { User } \\
\%(\mathrm{n})\end{array}$ & $\begin{array}{l}\text { Non-user } \\
\%(\mathrm{n})\end{array}$ \\
\hline Gender & & & \\
Female & $66.2(133)$ & $80.5(70)$ & $55.3(63)$ \\
Male & $33.8(68)$ & $19.5(17)$ & $44.7(51)$ \\
\hline Age group (years) & & & \\
60 to 69 & $47.3(95)$ & $48.3(42)$ & $46.5(53)$ \\
70 to 79 & $34.3(69)$ & $28.7(25)$ & $38.6(44)$ \\
80 or more & $18.4(37)$ & $23.0(20)$ & $14.9(17)$ \\
Marital status & & & \\
With partner & $69.2(139)$ & $57.5(50)$ & $78.1(89)$ \\
Without partner & $30.8(62)$ & $42.5(37)$ & $21.9(25)$ \\
\hline & & & to be continued
\end{tabular}


Continuation of Table 1

\begin{tabular}{|c|c|c|c|}
\hline Variables & $\begin{array}{l}\text { Total } \\
\%(\mathrm{n})\end{array}$ & $\begin{array}{l}\text { User } \\
\%(\mathrm{n})\end{array}$ & $\begin{array}{l}\text { Non-user } \\
\% \text { (n) }\end{array}$ \\
\hline \multicolumn{4}{|l|}{ Education } \\
\hline Illiterate & $9.5(19)$ & $9.2(8)$ & $9.7(11)$ \\
\hline Incomplete elementary education & $65.0(130)$ & $69.0(60)$ & $61.9(70)$ \\
\hline Complete primary education & $10.0(20)$ & $6.9(6)$ & $12.4(14)$ \\
\hline Incomplete high education & $3.5(7)$ & $2.3(2)$ & $4.4(5)$ \\
\hline Complete high education & $7.5(15)$ & $9.2(8)$ & $6.2(7)$ \\
\hline Incomplete higher education & $1.5(3)$ & $1.1(1)$ & $1.8(2)$ \\
\hline Complete higher education & $3.0(6)$ & $2.3(2)$ & $3.6(4)$ \\
\hline \multicolumn{4}{|l|}{ Family Income (MS) } \\
\hline 1 to 3 & $79.1(159)$ & $85.1(74)$ & $74.6(85)$ \\
\hline 3 or over to 5 & $13.4(27)$ & $11.5(10)$ & $14.9(17)$ \\
\hline 5 or over to 10 & $5.5(11)$ & $2.3(2)$ & $7.9(9)$ \\
\hline Over 10 & $2.0(4)$ & $1.1(1)$ & $2.6(3)$ \\
\hline \multicolumn{4}{|l|}{ Presence of chronic disease } \\
\hline Yes & $79.6(160)$ & $83.9(73)$ & $76.3(67)$ \\
\hline No & $20.4(41)$ & $16.1(14)$ & $23.7(27)$ \\
\hline \multicolumn{4}{|l|}{ Symptoms suggestive of depression } \\
\hline Yes & $21.9(44)$ & $34.5(30)$ & $12.3(14)$ \\
\hline No & 78.1 (157) & $65.5(57)$ & 87.7 (100) \\
\hline
\end{tabular}

$\mathrm{MS}=$ minimum salary; $1 \mathrm{MS}=\mathrm{R} \$ 880.00$

Table 2. Distribution of frailty components among elderly users and non-users of antidepressants in a municipal region in the south of Brazil, 2016.

\begin{tabular}{|c|c|c|c|c|c|}
\hline Component & $\begin{array}{l}\text { Total } \\
\%(\mathrm{n})\end{array}$ & $\begin{array}{l}\text { User } \\
\%(\mathrm{n})\end{array}$ & $\begin{array}{l}\text { Non-user } \\
\%(\mathrm{n})\end{array}$ & $p$ & OR (CI95\%) \\
\hline \multicolumn{6}{|l|}{ Fatigue } \\
\hline Yes & $35.3(71)$ & $47.1(41)$ & $26.3(30)$ & $0.002^{*}$ & $2.50(1.38-4.51)$ \\
\hline No & $64.7(130)$ & $52.9(46)$ & $73.7(84)$ & & \\
\hline \multicolumn{6}{|c|}{ Low gait speed } \\
\hline Yes & $23.4(47)$ & $32.2(28)$ & $16.7(19)$ & $0.010^{*}$ & $2.37(1.22-4.62)$ \\
\hline No & $76.6(154)$ & $67.8(59)$ & $83.3(95)$ & & \\
\hline \multicolumn{6}{|c|}{ Unintentional weight loss } \\
\hline Yes & $16.4(33)$ & $26.4(23)$ & $8.8(10)$ & $0.001 *$ & $3.74(1.67-8.36)$ \\
\hline No & $83.6(168)$ & $73.6(64)$ & $91.2(104)$ & & \\
\hline \multicolumn{6}{|c|}{ Low grip strength } \\
\hline Yes & $18.9(38)$ & $21.8(19)$ & $16.7(19)$ & 0.353 & $1.40(0.68-2.84)$ \\
\hline No & $81.1(163)$ & $78.2(68)$ & $83.3(95)$ & & \\
\hline \multicolumn{6}{|c|}{ Low level of physical activity } \\
\hline Yes & $13.4(27)$ & $14.9(13)$ & $12.3(14)$ & 0.583 & $1.25(0.56-2.82)$ \\
\hline No & $86.6(174)$ & $85.1(74)$ & $87.7(100)$ & & \\
\hline
\end{tabular}

${ }^{*} p<0.05$ 
It was found that elderly persons who used tricyclic antidepressants had a greater chance of frailty (OR=2.60 / CI 95\% 1.16 - 5.80) than those in the non-users group. A greater risk of frailty was not found among users of Selective Serotonin Reuptake Inhibitor antidepressants in comparison with the non-user group (OR=1.42 / CI 95\% 0.70 - 2.89).

When the use of antidepressants that were potentially inappropriate for the elderly was analyzed, it was found that the users of such inappropriate drugs had a 2.39 (CI 95\% 1.14 - 4.96) times greater chance of frailty than the non-user group. The inappropriate drugs used included amitriptyline, imipramine, nortriptyline and paroxetine.

\section{DISCUSSION}

The sociodemographic characteristics and health conditions of the studied population are similar to studies with Brazilian elderly persons that evaluated the use of antidepressants ${ }^{8,9}$, with a predominance of women, low educational levels, low incomes and the presence of chronic diseases; characteristics frequently present in the Brazilian population and which were also associated with a condition of frailty among Brazilian elderly persons ${ }^{1,22 .}$

The results of the present study also identified an association between antidepressant use and frailty. The elderly in the user group had a greater chance of frailty than those in the non-user group. These data are in line with the follow-up study by Lakey et al. ${ }^{12}$ with 27,652 women aged between 65 and 79 in the USA, which identified a greater risk of frailty among antidepressant users both with and without depressive symptoms.

The scientific evidence regarding the relationship between depressive symptoms and frailty has been widely explored in both Brazilian and non-Brazilian literature ${ }^{1,2,5}$. However, most of these studies do not consider the use of antidepressants as a potential interferer of frailty among the elderly ${ }^{10,11}$. Considering that frailty is an inherent condition of senescence, and due to the decline of the musculoskeletal, neuroendocrine and immunological systems ${ }^{3}$, the analysis of drug use is important in the monitoring of the elderly, especially in primary care.
Furthermore, most studies of depression and its treatment are conducted with a young population. The response of the elderly to antidepressant treatment may differ from this population, however, due to their physiological and health conditions, such as the presence of comorbidities and the use of multiple medications ${ }^{23}$, further recommending studies that include the use of antidepressants among the elderly.

Among the components of frailty, low walking speed, fatigue and unintentional weight loss were associated with the use of antidepressants. The use of antidepressant as a risk factor for a reduction in gait speed was identified in the studies of Groot et al. ${ }^{13}$ of elderly persons in Amsterdam and Donoghue et al. ${ }^{24}$ with elderly Irish persons. Among the potential adverse effects of antidepressants are repercussions on motor skills, such as an increased risk of falls, fractures and the impairment of functional capacity, which may be related to the impairment of gait ${ }^{16,25}$. These results highlight the importance of the monitoring of the elderly using antidepressants and protocols that evaluate the real necessity of the prescription of these drugs, considering the risk of iatrogenic diseases related to their use.

The association between antidepressant use and unintentional weight loss may be related to the emotional aspects of the elderly themselves, but there is also evidence that the presence of depressive symptoms and use of antidepressants may promote weight loss, especially those belonging to the serotonin reuptake inhibitor class ${ }^{26,27}$. Serotonin, the main neurotransmitter on which these drugs work, may act as an appetite regulator and in the choice of macronutrients, promoting appetite reduction and a preference for protein foods, which may lead to changes in body weight ${ }^{28}$.

Weight loss in old age, especially muscle mass reduction, can affect the pharmacokinetics of medications, constituting a risk for the elderly, as in the case of tricyclic antidepressants, which in this population present a higher risk of sedation and falls. Lakey et al. ${ }^{12}$ also found a risk among users of tricyclic antidepressants. In addition, these authors identified a risk among elderly persons using selective serotonin reuptake inhibitors, which differs from 
the present study, in which there was no greater risk among users of this class of drug in comparison with non-users.

Fatigue was another component of frailty associated with the use of antidepressants. This result refers to physical and mental exhaustion, which is one of the characteristics found in subjects with depression. Studies have shown that fatigue is the component that most affects the mental and emotional evaluation of the elderly ${ }^{29,30}$.

Tricyclic antidepressants act by inhibiting the reuptake of serotonin and norepinephrine, with a highly anticholinergic effect in terms of adverse effects such as blurred vision and the impairment of memory and delirium, increasing the risk of psychomotor disorders and the occurrence of falls ${ }^{18}$. In addition, there may be other central effects related to weakness and fatigue. Given these effects, the drugs in this class are classified as potentially inappropriate for the elderly according to the Beers criteria $^{18}$. In this context, the present study found that the use of inappropriate antidepressants increases the chance of frailty, which demonstrates the need to incorporate the indications of these criteria into the clinical practice of the elderly, especially in primary health care.

The association between frailty and the use of potentially inappropriate drugs was also verified in non-Brazilian studies such as those by Cullinan et al. ${ }^{31}$ in Ireland and Récoché et al. ${ }^{32}$ in France. In Brazil, the study by Cassoni et al. ${ }^{33}$ with elderly persons from the city of São Paulo taking part in the SABE (Health, Welfare and Aging) study found that $40.1 \%$ of users of inappropriate drugs were considered frail. It is inferred that the use of these drugs can have negative consequences on the health of the elderly and when associated with frailty can further impair their health and life condition. The association of the use of potentially inappropriate drugs with frailty emphasizes the importance of incorporating the Beers' criteria into the clinical practice of elderly care ${ }^{18}$ as an instrument to guide prescriptions, with a view to the selection of suitable drugs for the characteristics of the elderly population and the prevention of potential adverse effects which may compromise the health of the senescent individual.

The best way to care for an aging society is to reduce the risk of frailty and the loss of autonomy. To achieve this different health professionals must work to achieve safe and effective geriatric pharmacology, as this is the population which most consumes medication, and such medication is potentially more harmful among them ${ }^{9,31,32}$.

In this context, it is necessary to evaluate and accompany the frailty syndrome in clinical practice, especially when instituting drug therapies that may have an impact on this condition, such as the use of antidepressants, which require the constant monitoring of treatment to identify problems and the application of interventions necessary for the promotion of care by health teams $\mathrm{s}^{32,33}$.

However, the design of the present study did not allow the monitoring or evaluation of the impact of antidepressant treatment on the capabilities of the elderly. To achieve this, the physical-functional evaluation of the elderly at the beginning of treatment and throughout its course would be required through the performance of systematic evaluations. Considering that the results suggest that there is an association between the use of antidepressants and frailty, other studies can perform this follow-up evaluation to identify to what degree antidepressants interfere with this syndrome.

\section{CONCLUSION}

The results of the present study demonstrate the association between antidepressant use and frailty, especially in the gait speed, fatigue and unintentional weight loss components.

These findings highlight the need for the clinical evaluation of the risks and benefits of prescribing antidepressants to elderly individuals. When treatment is instituted, the regular monitoring and evaluation of geriatric characteristics such as frailty is required to identify potential harm and to ensure the safety and quality of life of elderly users of these medications. 


\section{REFERENCES}

1. Pegorari MS, Tavares DMS. Fatores associados à síndrome de fragilidade em idosos residentes em área urbana. Rev Latinoam Enferm. 2014;22(5):874-82.

2. Hajek A, Brettschneider C, Posselt T, Lange C, Mamone S, Wiese B, et al. Predictors of frailty in old age: Results of a longitudinal study. J Nutr Health Aging. 2016;20(9):952-57.

3. Fried L, Tangen CM, Walston J, Newman AB, Hirsch C, Gottdiener J, et al. Frailty in older adults: evidence for a phenotype. J Gerontol Ser A Biol Sci Med Sci. 2001;56(3):146-56.

4. Vermeiren S, Vella-Azzopardi R, Beckwée D, Habbig AK, Scafoglieri A, Jansen B, et al. Frailty and the prediction of negative health outcomes: a metaanalysis. J Am Med Dir Assoc. 2016;17(12):1163-1163.

5. Buttery AK, Busch MA, Gaertner B, Scheidt-Nave C, Fuchs J. Prevalence and correlates of frailty among older adults: findings from the German health interview and examination survey. BMC Geriatr. 2015;15(22):1-9.

6. Barcelos-Ferreira R, Izbicki R, Steffens DC, Bottino CMC. Depressive morbidity and gender in communitydwelling Brazilian elderly: systematic review and metaanalysis. Int Psychogeriatr. 2010;22(5):712-26.

7. Brunoni AR, Nunes MA, Figueiredo R, Barreto SM, Fonseca MJM, Lotufo PA, et al. Patterns of benzodiazepine and antidepressant use among middleaged adults. The Brazilian longitudinal study of adult health (ELSA-Brasil). J Affect Disord. 2013;151(1):71-7.

8. Noia AS, Secoli SR, Duarte YAO, Lebrão ML, Lieber NSR. Fatores associados ao uso de psicotrópicos por idosos residentes no Município de São Paulo. Rev Esc Enferm USP. 2012;46(Esp):38-43.

9. Vicente ART, Castro-Costa E, Diniz BS, Firmo JOA, Lima-Costa MF, Loyola Filho AI. Antidepressant use and associated factors among the elderly: the Bambui Project. Ciênc Saúde Coletiva. 2015;20(12):3797-804.

10. Briana M, Lauren E, Matt L, Moon C, Kate L. Depression and frailty in later life: a synthetic review. Int J Geriatr Psychiatry. 2012;27(9):879-92.

11. Benraad CE, Kamerman-Celie F, Munster BCV, Voshaar RCO, Spijker J, Rikkert MGMO. Geriatric characteristics in randomised controlled trials on antidepressant drugs for older adults: a systematic review. Int J Geriatr Psychiatry. 2016;31(9):990-1003.

12. Lakey SL, LaCroix AZ, Gray SL, Borson S, Williams CD, Calhoun D, et al. Antidepressant use, depressive symptoms, and incident frailty in women aged 65 and older from the Women's Health Initiative Observational Study. J Am Geriatr Soc. 2012;60(5):854-61.
13. Groot MH, Campen JPCM, Kosse NM, Vries OJ, Bijinen JH, Lamoth CJC. The Association of Medication-Use and Frailty-Related Factors with Gait Performance in Older Patients. Plos ONE. 2016;11(2):1-15.

14. DATASUS. Sistema de Informação da Atenção Básica. Brasília, DF: SIAB; 2014.

15. Field A. Descobrindo a estatística usando o SPSS. $2^{\text {a }}$ ed. Porto Alegre: Artmed; 2009.

16. Almeida OP, Almeida SA. Short versions of the geriatric depression scale: a study of their validity for the diagnosis of a major depressive episode according to ICD-10 and DSM-IV. Int J Geriatr Psychiatry. 1999; 14(10):858-65.

17. World Health Organization Collaborating Centre for Drug Statistics Methodology. Anatomical therapeutic chemical ATC/DDD Índex [Internet]. Nydalen: WHOCC; 2016 [acesso em 23 out. 2016]. Disponível em: http://www.whocc.no/atc_ddd_index/

18. American Geriatrics Society. American Geriatrics Society 2015 Updated Beers Criteria for Potentially Inappropriate Medication Use in Older Adults. J Am Geriatr Soc. 2015;63(11):2227-46.

19. Batistoni SST, Neri AL, Cupertino APFB. Validade da escala de depressão do Center for Epidemiological Studies entre idosos brasileiros. Rev Saúde Pública. 2007;41(4):598-605.

20. Santos EGS. Perfil de fragilidade em idosos comunitários de Belo Horizonte: um estudo transversal [dissertação]. Belo Horizonte: Universidade Federal de Minas Gerais; 2008.

21. Fattori A, Neri AL, Santimaria MR, Yassuda MS, Siqueira MEC. Indicadores de Fragilidade. In: Neri AL, organizadora. Fragilidade e qualidade de vida na velhice. Campinas: Alínea; 2013. (Coleção Velhice e Sociedade).

22. Mello AC, Engstrom EM, Alves LC. Fatores sociodemográficos e de saúde associados à fragilidade em idosos: uma revisão sistemática de literatura. Cad Saúde Pública. 2014;30(6):1-25.

23. Wiese BS. Geriatric depression: the use of antidepressants in the elderly. BC Med J. 2011;53(7):341-7.

24. Donoghue OA, O’Hare C, King-Kallimanis B, Kenny RA. Anti-depressants are independently associated with gait deficits in single and dual task conditions. Am J Geriatr Psychiatry. 2015;23(2):189-99.

25. Téllez-Lapeira JM, Hidalgo JLT, Gálvez-Alcaraz L, Párraga-Martínez I, Boix-Gras C, García-Ruiz A. Consumo de ansiolíticos e hipnóticos y factores asociados en laspersonas mayores. Rev Esp Geriatr Gerontol. 2017;52(1):31-4. 
26. Khera R, Murad MH, Chandar AK, Dulai PS, Wang Z, Prokop LJ, et al. Association of pharmacological treatments for obesity with weight loss and adverse events: a systematic review and meta-analysis. JAMA. 2016;315(22):2424-34.

27. Patel K, Allen S, Haque MN, Angelescu I, Baumeister D, Tracy DK. Bupropion: a systematic review and meta-analysis of effectiveness as an antidepressant. Ther Adv Psychopharmacol. 2016;6(2):99-144.

28. Peixoto HGE, Vasconcelos IAL, Sampaio ACM, Ito MK. Antidepressivos e alterações no peso corporal. Rev Nutr. 2008;21(3):341-8.

29. Chang YW, Chen WL, Lin FG, Fang WH, Yen MY, Hsieh CC. Frailty and its impact on health-related quality of life: a cross-sectional study on elder community-dwelling preventive health service users. Plos ONE. 2012;7(5):1-10.
30. Tavares DMS, Almeida EG, Ferreira PCS, Dias FA, Pegorari MS. Status de fragilidade entre idosos com indicativo de depressão segundo o sexo. J Bras Psiquiatr. 2014;63(4):347-53.

31. Cullinan S, O’Mahony D, O’Sullivan D, Byrne S. Use of a frailty index to identify potentially inappropriate prescribing and adverse drug reaction risks in older patients. Age Ageing. 2016;45(1):115-20.

32. Récoché I, Lebaudy C, Cool C, Sourdet S, Piau A, Lapeyre-Mestre M, et al. Potentially inappropriate prescribing in a population of frail elderly people. Int J Clin Pharm. 2017;39(1):113-9.

33. Cassoni TCJ, Corona LP, Romano-Lieber NS, Secoli SR, Duarte YAO, Lebrão ML. Uso de medicamentos potencialmente inapropriados por idosos do Município de São Paulo, Brasil: Estudo SABE. Cad Saúde Pública. 2014;30(8):1708-20. 